\title{
Dormindo com o Inimigo: Uma Crítica ao Conceito de Confiança
}

João Feres Júnior

José Eisenberg

$\mathrm{E}$ m seu survey mundial de 1990-93, o cientista político Ronald Inglehart perguntou aos seus entrevistados: "Em geral, você diria que a maioria das pessoas é confiável ou que se deve ser precavido ao lidar com elas?" (Generally speaking, would you say that most people can be trusted or that you can't be too careful in dealing with people?). No Brasil, somente $7 \%$ dos entrevistados responderam que a maioria das pessoas é digna de confiança, o resultado mais baixo entre os 43 países pesquisados.

Há inúmeras maneiras de interpretar este resultado, e muitas delas provavelmente atribuiriam o baixo nível de confiança interpessoal dos brasileiros a um conjunto de características de nossa cultura cívica e política. Inglehart (1999) sugere que o grau de confiança interpessoal de uma determinada sociedade está diretamente relacionado à estabilidade democrática e às tradições culturais-religiosas sedimentadas. De acordo com esse autor, democracias estáveis e protestantismo produzem um alto grau de confiança interpessoal. Instabilidade democrática e catolicismo, por sua vez, produzem pessoas desconfiadas.

Neste artigo, pretendemos mostrar que as interpretações dos resultados obtidos nesses surveys são muitas vezes imprecisas ou equivocadas, visto que ignoram importantes diferenças entre as sociedades pesquisadas no âmbito de suas culturas cívica e política. Argumentamos que parte desse equívoco se deve à fragilidade analítica com a qual o

DADOS - Revista de Ciências Sociais, Rio de Janeiro, Vol. 49, n-3, 2006, pp. 457 a 481. 
conceito de confiança interpessoal é formulado, pois tal formulação desconsidera o papel que instituições que adjudicam conflitos (por exemplo, o Direito) têm na mediação de relações interpessoais em uma sociedade. Conseqüentemente, as respostas obtidas nas pesquisas de opinião pública referentes ao conceito de confiança acabam por traduzir uma dimensão distinta daquela originalmente pretendida por aqueles que as realizam. Em suma, nosso argumento é que, devido à sua fragilidade analítica, o conceito de confiança interpessoal é ineficaz enquanto ferramenta de medição empírica, conduzindo, portanto, a conclusões nomológicas - i.e., generalizações teóricas indutivas baseadas em evidências empíricas - equivocadas.

Devido à impropriedade do conceito, a descoberta da relação necessária entre confiança interpessoal e estabilidade democrática, baseada nas observações empíricas do survey, também deve ser colocada sob suspeita. Não há, a princípio, nenhuma razão para crer que este tipo de confiança não possa existir, ou mesmo vicejar, em ambientes de degradação da cultura democrática, segregação, autoritarismo, ou mesmo em sociedades fortemente hierarquizadas. Em outras palavras, a fragilidade analítica dessa categoria suscita aspectos normativos preocupantes que a abordagem empiricista dos estudos de política comparada não está equipada para enfrentar.

Na próxima seção, traçamos a filiação teórica da tese culturalista de Inglehart, segundo a qual a confiança interpessoal é um produto da herança religiosa das sociedades contemporâneas, para depois apontar inconsistências nos resultados de sua pesquisa que põem em dúvida essa mesma tese. Na seção seguinte, examinamos a variação semântica do conceito de "confiança" em algumas das mais faladas línguas ocidentais com dois objetivos: apontar para os problemas que sua tradução e aplicação na pesquisa empírica podem acarretar, e revelar as várias significações que o termo e expressões compostas como "confiança interpessoal" e "confiança pessoal" podem adquirir em contextos distintos. Em seguida, demonstramos os problemas teóricos decorrentes do conceito de confiança interpessoal e propomos o conceito de confiança política, ou melhor, confiança em instituições como alternativa. Na seção final, apresentamos as implicações desta crítica para uma teoria democrática e explicamos como a confiança em instituições pode funcionar como ferramenta de aferição de regimes políticos reais ${ }^{1}$. 


\section{DESCONFIANDO DO CONCEITO DE CONFIANÇA INTERPESSOAL}

Há duas décadas Ronald Inglehart tem comparado pesquisas de opinião pública sobre aspectos socioculturais e políticos de vários países primeiro no contexto mais restrito do Eurobarometer, no início dos anos 1980, e mais recentemente com o World Values Survey. Já em sua terceira edição, o World Values Survey abrange 65 países nos cinco continentes. Sua amostragem cobre, segundo dados do próprio autor, $80 \%$ da população mundial. Em cada país a pesquisa é feita por grupos locais e com verba local, sendo que o trabalho final de tabulação e análise fica por conta de Inglehart e sua equipe do Instituto de Pesquisa Social da Universidade de Michigan.

Dentre os trabalhos produzidos por Inglehart usando dados do survey mundial encontra-se "Trust, Well-Being and Democracy", artigo publicado em Warren (1999), em que o autor interpreta resultados dos dois primeiros surveys mundiais levados a cabo em 1990-91 e 1995-98, dando ênfase especial às relações entre confiança, bem-estar e democracia (Inglehart, 1999). Em termos gerais, o artigo deve ser entendido como um esforço de se argumentar, através de interpretações dos dados dos surveys, que o nível de confiança interpessoal é, em grande parte, um produto da cultura política de um povo, e que essa confiança está diretamente relacionada à estabilidade do regime democrático. Recuperando a tradição culturalista das ciências sociais norte-americanas, Inglehart pretende reconduzir o conceito de cultura política a um lugar central na teoria democrática.

Inglehart apóia-se nos trabalhos de Robert Putnam (1993) e Francis Fukuyama (1995) para dizer que a confiança interpessoal é um elemento essencial para o desenvolvimento de democracias modernas. Segundo estes autores, esse tipo de confiança promove a cooperação entre estranhos, o que, por sua vez, é um elemento fundamental, no plano político, para a estabilidade das instituições representativas e, no plano econômico, para o funcionamento de sistemas de produção complexos de larga escala.

Essa tese, compartilhada por inúmeros cientistas sociais norte-americanos, é baseada na premissa do primado da cultura sobre o político e o econômico (Almond e Coleman, 1960; Almond e Verba, 1963), e consiste no maior legado da recepção acadêmica de Max Weber nos EUA do pós-guerra. Tal tese é a espinha dorsal da teoria da modernização - uma das abordagens sociocientíficas mais influentes e dura- 
douras nos EUA. Contudo, a recepção de Weber foi muito além da mera crença no primado da cultura na formação política de uma nação democrática. De A Ética Protestante e o Espírito do Capitalismo, os teóricos da modernização apropriaram o argumento de que o protestantismo em sua vertente puritana serviu de alicerce para o desenvolvimento da mentalidade capitalista. Fazendo vistas grossas para a tese weberiana da secularização do mundo moderno, esses acadêmicos construíram uma teoria na qual modernidade, capitalismo e protestantismo se tornam praticamente indissociáveis. Isso lhes permitiu reduzir a narrativa da modernidade a uma história do capitalismo protestante. Da mesma maneira, produziu-se uma geografia da modernidade em que os EUA, os países anglo-saxões e as nações germânicas protestantes, em ordem hierárquica decrescente, representam o moderno, enquanto o resto do mundo é descrito como tradicional (Lerner, 1967; Lipset, 1960; Rostow, 1960).

O poder simplificador da teoria da modernização foi além da equiparação do trinômio modernidade/capitalismo/protestantismo. Alguns autores também se apropriaram do termo "ocidente", argumentando que a narrativa weberiana da gênese da mentalidade capitalista corresponde à história recente da civilização ocidental (Millikan e Blackmer, 1961). Outros foram ainda além, dizendo que modernização e ocidentalização são de fato sinônimos de americanização (Blanksten, 1960; Lerner, 1967).

Inglehart não comete os mesmos arroubos triunfalistas de seus antecessores, mas reproduz basicamente o mesmo argumento. Ao notar que os níveis de confiança interpessoal nos países protestantes do hemisfério norte são em média maiores dos que os níveis em países católicos, o autor conclui que essa diferença se explica pela "herança cultural histórica" de cada povo. Ele também observa que o índice de confiança interpessoal tem uma alta correlação com o nível de riqueza e com o "nível de democracia" - entendido como um agregado do respeito a direitos civis e políticos e estabilidade institucional. Portanto, quatro variáveis estão em jogo: confiança interpessoal, nível de riqueza (modernização econômica), herança cultural histórica (religião) e democracia. Inglehart sugere que tanto o desenvolvimento econômico quanto o nível de confiança e a democracia são, de fato, produtos da herança religiosa. 
As preocupações empírico-comparativas de Inglehart ofuscam os problemas conceituais embutidos nas categorias que articulam seu argumento. $\mathrm{O}$ autor afirma de forma contundente que a confiança interpessoal é uma conseqüência da herança religiosa de um povo, mas ao mesmo tempo diz que seu texto não é lugar apropriado para discutir as "complexidades dessa relação". Uma análise de algumas dessas "complexidades", porém, demonstra que o poder explicativo de seu modelo é bastante reduzido. Mais precisamente, o conceito de confiança interpessoal em nada contribui para uma compreensão satisfatória das trajetórias econômicas e políticas dos países analisados. Pelo contrário, ele ofusca relações que verdadeiramente importam a uma interpretação comparativa adequada do funcionamento das instituições democráticas destes países e do nível de desenvolvimento econômico por eles alcançados. Comecemos com algumas dificuldades da lógica interna do argumento proposto.

Em primeiro lugar, a categoria "herança cultural histórica", que Inglehart reduz à religião atávica dominante em um país, é problemática. Inglehart empresta o argumento weberiano para argumentar que os altos níveis de confiança interpessoal nos países do Norte ocidental se devem à sua herança protestante. Contudo, o autor não explica como a herança comum confucionista, que ele atribui a China, Formosa, Japão e Coréia, contribui também para o alto nível de confiança interpessoal encontrado naqueles países. De fato, o grupo de países confucionistas parece negar as principais descobertas de Inglehart. A China apresenta o maior nível de confiança interpessoal entre seus pares, apesar de ser de longe o país mais pobre do grupo e certamente o menos "democrático". Nesse grupo, quanto maior a renda per capita (medida escolhida pelo autor) menor o nível de confiança - um fato que também contraria a teoria do autor. De novo, Inglehart esquiva-se do desafio de explicitar quais seriam as complexidades e diferenças da religião confucionista nestes países que pudessem explicar tal resultado. Ao leitor só resta a dúvida quanto à aplicabilidade do modelo proposto.

Em segundo lugar, Inglehart argumenta que o baixo nível de confiança interpessoal em países católicos é um produto da hierarquia centralizada da Igreja, que submetia pessoas ao poder de autoridades distantes com as quais elas não podiam manter relações interpessoais. Em contraposição, as pequenas comunidades protestantes proporcionaram um ambiente propício para o exercício da confiança. Mais uma vez, Inglehart ignora as complexidades e diferenças internas aos sub- 
grupos religiosos que ele mesmo adota. Neste caso, é o próprio protestantismo, a religião que tanto importa para a comprovação de sua tese, que é tratado com pouco cuidado. Afinal, o exemplo mais caro de país moderno democrático protestante usado pelo autor, depois dos EUA, é a Inglaterra. Contudo, devemos notar que o anglicanismo, enquanto doutrina religiosa, é muito similar ao catolicismo, tanto no que diz respeito à doutrina em geral quanto à centralização hierárquica da Igreja. De fato, ao unir o comando da Igreja e do Estado nas mãos de uma só pessoa, o rei, a Inglaterra caminhou em um sentido contrário ao da idéia "moderna" da separação entre essas duas esferas. Em seus estudos, Weber nunca se arriscou a tentar explicar como o anglicanismo pode ter gerado uma mentalidade capitalista, preferindo concentrar sua análise nos grupos puritanos radicais que imigraram para os EUA fugindo da perseguição religiosa que sofriam por parte dos mesmos anglicanos. O caso inglês evidentemente não se enquadra de maneira trivial no modelo proposto por Inglehart.

Mais preocupante ainda é a combinação da crença de Inglehart nas virtudes do protestantismo (sejam elas quais forem) com sua falta de interesse em examinar os detalhes da relação entre o conteúdo das diversas doutrinas protestantes com as motivações orientadas para a confiança. A tese de Inglehart a favor do protestantismo é tão verdadeira quanto à conclusão de que a confiança interpessoal é uma característica do povo germânico. Afinal de contas, a maioria dos povos com altos níveis de confiança interpessoal, democracia e desenvolvimento econômico são de "cultura" e língua germânicas. Contudo, o autor não se arrisca a fazer tal correlação. Muito popular nos meios intelectuais norte-americanos do século XIX e início do XX, o pangermanismo caiu em desgraça com a derrocada do regime nazista na Segunda Guerra Mundial. Apesar de ainda sobreviverem nas margens do mundo acadêmico (Martin, 1990), argumentos abertamente raciais felizmente não são mais aceitos no mainstream das ciências sociais americanas. A título de nota para futuros estudos, devemos ficar atentos para a possibilidade de que a recepção da teoria de Weber nos EUA tenha servido como instrumento de continuação, escamoteamento à reciclagem das teorias racistas do passado, principalmente o pangermanismo e o anglo-saxonismo.

$\mathrm{O}$ argumento da hierarquia religiosa como fonte da falta de confiança, de fato o único fornecido por Inglehart, torna-se ainda mais duvidoso quando notamos que, uma vez controlada a variável econômica (renda 
per capita), os países reunidos pelo autor sob o rótulo "cristianismo ortodoxo" têm um nível de confiança interpessoal significativamente mais alto que países protestantes. Mas não seriam as igrejas ortodoxas também caracterizadas por um alto grau de hierarquização? Ou seja, as explicações oferecidas por Inglehart aplicam-se a alguns casos, mas não a outros. A situação complica-se ainda mais quando notamos que, uma vez feito o controle da variável econômica, até mesmo países católicos apresentam um nível de confiança interpessoal tão "bom" ou "melhor" que o de seus pares protestantes. Em suma, a categoria "herança cultural histórica" parece se sustentar sobre explicações ad hoc que o autor não aplica judiciosamente a todos os casos estudados.

São, contudo, as conclusões que podem ser derivadas do texto de Inglehart que nos preocupam mais. $\mathrm{O}$ autor insiste no fato de que a "herança cultural histórica" está profundamente entranhada no povo, e, portanto, só pode sofrer mudanças significativas em um longo prazo. Isso significa dizer que, por ser presa de sua cultura atávica, uma comunidade política não é agente de sua própria história. O horizonte de expectativas gerado por esse raciocínio é no mínimo desalentador, pois indicaria que aqueles que hoje se encontram em uma posição "inferior" têm poucas chances de melhora significativa, a não ser que sejam submetidos a um processo tout court de aculturação ou colonização por parte dos protestantes.

Do ponto de vista metodológico, vale lembrar que o conjunto de suposições e hipóteses, apresentados por Inglehart em "Trust, Well-Being and Democracy", é feito a partir das respostas a uma única pergunta do World Survey: "Em geral, você diria que a maioria das pessoas é confiável ou que se deve ser precavido ao lidar com elas?" A metodologia de surveys, instrumentos que sem dúvida enriquecem nossa compreensão sociológica das sociedades de massa, não recomenda que se construam indicadores quantificados a partir de uma única pergunta. Há ainda inúmeros problemas associados à aplicação de questionários que colocam seriamente em dúvida a qualidade da compreensão de perguntas pelos respondentes, em particular em países onde o nível de escolaridade médio da população é baixo. Em se tratando de um survey comparativo mundial, em que a pergunta é traduzida para diversas línguas, adiciona-se a dificuldade cognitiva de que expressões com conotação moral evidente (como o conceito de confiança) adquiram significados bastante distintos nos contextos lingüístico-semânticos em que são utilizadas. Como veremos na seção seguinte, uma análise etimológica das 
palavras que exprimem a idéia de confiança em algumas línguas do tronco indo-europeu já aponta para uma significativa diferença.

\section{CONFIANÇA: UMA BREVE ARQUEOLOGIA ETIMOLÓGICA}

Inglehart parece não se importar com o fato de que a medida experimental da confiança interpessoal pode ser prejudicada em decorrência dos diferentes significados da palavra confiança nas muitas línguas dos países em que o survey foi aplicado. Ora, sabemos que a maioria dos seres humanos vive em comunidades lingüísticas razoavelmente estáveis, e que os significados atribuídos aos termos de uma língua são produtos de experiências sociais compartilhadas dentro de cada uma dessas comunidades. Como conseqüência do fato de a língua adquirir significado através da experiência vivida de coletividades humanas, os campos semânticos de muitos termos complexificam-se e diferenciam-se. Toda pessoa que algum dia se empenhou seriamente em fazer uma tradução passou pela experiência de não poder achar termos na língua de destino que correspondam perfeitamente aos termos da língua de origem. Não raro, expressões inteiras têm que ser reescritas, e o tradutor, mais cedo ou mais tarde, se dá conta de que seu trabalho é de fato uma forma de interpretação ${ }^{2}$.

Portanto, a questão que se coloca à medida experimental é: como se produzir uma pergunta que signifique exatamente a mesma coisa em 65 contextos lingüísticos diferentes? O alto grau de dificuldade dessa tarefa, sequer comentado pelo nosso autor, coloca em questão o significado e a consistência de suas descobertas. Nosso objetivo principal nesta seção, contudo, não é apenas identificar mais um problema na análise de Inglehart, mas apontar para os componentes semânticos divergentes que caracterizam o termo confiança e seus correlatos em algumas das principais línguas indo-européias.

Comecemos pelo inglês, que é nos dias de hoje a primeira língua na academia ocidental e a língua originária do survey de Inglehart. Analisando detalhadamente as citações ilustrativas do longo verbete do substantivo trust no Oxford English Dictionary (Simpson, Weiner et alii, 1991), percebe-se que, até o século XVI, o termo era utilizado em sentido não-metafórico, para se referir a uma relação de confiança entre amigos, parentes ou pessoas conhecidas, como também era usado para se referir à confiança em Deus. A partir do século XVI, mas sem perder seus conteúdos semânticos anteriores, trust passa a ser usado para sig- 
nificar "comprar em confiança", ou melhor, comprar fiado, a crédito. Ao redor desse período, o termo também é apropriado pela terminologia jurídica para significar a relação em que uma pessoa se torna tutora de bens de outra pessoa. As palavras disponíveis nas principais línguas neolatinas que melhor traduzem a noção de trust são, em sua maioria, derivadas do termo latino fides: confiança em português, confianza em espanhol, confiance em francês, e fiducia em italiano. Contudo, os significados atribuídos ao termo fides em latim parecem não corresponder exatamente ao conteúdo semântico de trust em inglês. Uma vez que não nos é possível aqui proceder a uma análise pormenorizada dos termos de cada língua, vamos direto à língua fonte.

A Latin Dictionary (Andrews, Freund et alii, 1955) define fides como "trust in a person or thing". À primeira vista, portanto, a definição parece não distar muito de seu correspondente em inglês. Contudo, uma leitura mais cuidadosa do verbete revela que, paralelamente ao seu significado "pessoal", fides também queria dizer crédito monetário. Ou seja, diferentemente do termo trust em inglês, que adquiriu o significado de crédito tardiamente, a forma latina fides aparece associada ao crédito já no período da República romana. Autores como Plauto, Júlio César e Cícero empregavam o termo das duas maneiras, como as abonações do dicionário nos permitem constatar. Confirmando a importância do aspecto "comercial" na concepção romana, mesmo entre abonações que ilustram o caráter pessoal de fides, há referências a promessas de pagamento.

O que dizer dessas diferenças entre o uso do termo em inglês e em latim? A confiança comercial difere da pessoal em um aspecto muito importante: ela é mais claramente limitada por precondições. Uma relação de crédito, ou mais geralmente, de transferência de um bem a outrem com vistas a um pagamento (retribuição) futuro, é delimitada no espaço e no tempo. Seus termos são, em geral, claramente estabelecidos entre as partes, não raro na forma de um contrato, que por sua vez está sujeito à ação reguladora da lei. Isso não se aplica à confiança pessoal, cuja existência e manutenção envolvem primordialmente aspectos morais e emocionais do âmbito privado. As precondições da confiança pessoal, quando existem, não são necessariamente explicitadas e raramente se tornam assunto de negociação entre as partes. Ademais, contrário à relação comercial, o depositário da confiança pessoal supostamente não age com vistas a qualquer benefício próprio ou lucro. 
Estas evidências parecem apontar para o fato de a confiança pessoal ocupar um espaço maior no campo semântico de trust. Por exemplo, mesmo um termo do vocabulário jurídico inglês como trustee, que é uma invenção do início da Idade Moderna, não denota uma relação contratual do tipo sugerido pela confiança comercial. Pois, enquanto o beneficiário depende da confiança depositada no trustee, este não recebe nenhum benefício dessa relação, a não ser a satisfação moral de exercitar de maneira virtuosa a confiança que lhe foi depositada.

Mas é nos textos de teoria política, fonte pouco explorada no verbete do Oxford English Dictionary, que identificamos a pista mais importante. Sem pretensões de um exame extensivo da incorporação dessa palavra ao pensamento político inglês, gostaríamos de fazer algumas observações que nos parecem cruciais. Foi também no início da Idade Moderna que a palavra trust adquiriu o status de conceito em teoria política. John Locke é, com certeza, o autor que mais se notabilizou por conferir à palavra trust um sentido verdadeiramente político. Contudo, Thomas Hobbes já havia feito amplo uso do termo no Leviatã. Sua definição de trust é a seguinte: "To believe, to trust, to rely on another, is to honour him; sign of opinion of his virtue and power. To distrust, or not believe, is to dishonour" 3 .

Apesar de dar a trust um tom aparentemente social, associando o termo ao poder e à virtude, Hobbes iguala o termo à "crença" (belief), atitude que repetidamente associa à irracionalidade e/ou aos argumentos escolásticos baseados na noção de auctoritas. Da mesma forma, o autor, em outra passagem, argumenta que a ignorância é também uma fonte de confiança (Hobbes, 1983:63). Para Hobbes, a confiança só pode se libertar da irracionalidade através do contrato social, ou mais especificamente, da submissão das partes envolvidas em uma relação de confiança submetida à força da espada. Em outras palavras, a confiança pessoal, aquela baseada na afeição e na "crença" nas qualidades de outrem, não serve como valor de regulação da vida coletiva. Só a confiança comercial (contratual), quando garantida pelo poder do soberano, tem conteúdo racional. Em suma, para Hobbes, a lei é precondição necessária para o exercício da confiança.

Enquanto Hobbes usa o político para redefinir a confiança em termos comerciais, Locke confere à confiança um verdadeiro sentido político, utilizando-a no Segundo Tratado como um elemento crucial de seu argumento contra o patriarcalismo político. $\mathrm{O}$ autor começa por analisar a 
confiança pessoal em seu contexto mais próprio: a família. A intenção é mostrar que a confiança dos filhos na autoridade paterna se justifica pela proximidade dos laços afetivos que unem a família. De maneira similar, sustenta Locke, as primeiras comunidades eram formadas por laços de amizade e parentesco, e, conseqüentemente, esse tipo de confiança de origem pessoal foi estendido aos seus líderes. Tanto no caso da família como no das pequenas sociedades primitivas, a confiança depositada no chefe pressupõe tacitamente que este olhe pelo bem comum.

Contudo, o crescimento e a complexificação da comunidade levam à degeneração desse tipo de relação protopolítica. Os líderes corrompem-se, passando a cuidar de seus próprios interesses e a oprimir as pessoas sob seu comando. Em outras palavras, a confiança pessoal, e, por conseguinte, o patriarcalismo, não pode mais servir como elemento principal de coesão social. Para resolver esse problema, Locke propõe um contrato social no qual as pessoas depositam no mandatário sua confiança, mas de maneira claramente limitada. A palavra trust continua a ser usada, mas agora com um outro sentido. Não se trata da confiança "irracional" depositada no pai ou no chefe clânico ${ }^{4}$, mas sim de uma confiança racional fundada explicitamente na manutenção do bem comum. A necessidade de "condicionar" a confiança ao respeito à vida, liberdade e propriedade dos cidadãos é tão forte que, sempre ao usar a palavra trust no texto, Locke em seguida reafirma as condições que limitam seu exercício.

O que esta rápida incursão pelo uso da palavra trust por esses teóricos políticos ingleses do início da Idade Moderna nos mostra, entre outras coisas, é que os autores trabalharam arduamente para redefinir a palavra trust, e que essa redefinição implica mitigar o forte conteúdo de confiança pessoal associado a ela. Em seu esforço para clarificar a mudança conceitual que pretende operar, Locke chega a chamar seu novo tipo de confiança política de fiduciary trust, apelando exatamente para a forma latina fides/fiducia para reforçar o aspecto semântico contratual e, assim, distingui-lo do aspecto pessoal do uso comum de trust (Locke, 1983:cap. XIII).

Em resumo, se no começo da Idade Moderna encontramos Hobbes e Locke tentando associar significados a trust que já faziam parte do campo semântico de fides há mais de 15 séculos, isso é porque os dois termos não eram semanticamente equivalentes. A noção de trust pare- 
ce estar fortemente ligada à idéia de confiança pessoal, enquanto fides sugeria, até para falantes do inglês, um tipo de confiança ligada a relações contratuais e comerciais. É interessante notar que nas línguas neolatinas, com a exceção do italiano, um prefixo con- foi adicionado ao radical de fides, o que reforça ainda mais o caráter de reciprocidade contratual do termo.

Essa constatação nos permite supor hipoteticamente que os significados associados a trust e a seus correlatos em línguas atuais da família germânica (i.e., Vertraung) podem ainda hoje ser razoavelmente diferentes dos significados associados aos derivados de fides nas línguas neolatinas. Em outras palavras, ao serem perguntados "generally speaking, would you say that most people can be trusted...?", os falantes de língua inglesa podem ter entendido que a expressão "most people can be trusted" se refere às pessoas sobre as quais a confiança pessoal pode ser depositada, isto é, aquelas pessoas que lhes são próximas - as que Charles Taylor, por exemplo, chama de "significant others". Por outro lado, falantes de línguas neolatinas teriam mais dificuldade de depositar "confiança" em "pessoas em geral" visto que as condições da relação de confiança não são dadas pelo enunciado da pergunta. Inglehart poderia ter refinado mais sua ferramenta de pesquisa, incluindo a pergunta "do you generally trust 'strangers'?", o que serviria de parâmetro para tentarmos reavaliar o entendimento que os respondentes tiveram da questão anterior. Em suma, a pesquisa comparativa de Inglehart, ao utilizar uma única pergunta cujo sentido moral pode ser variável por toda a amostra, produz um resultado potencialmente artificial. Parece-nos, além do mais, que estas diferenças no uso do termo confiança entre as línguas latinas (em geral, países católicos) e o inglês (países protestantes) é componente necessário a qualquer explicação mais robusta dos resultados encontrados por Inglehart.

\section{CONFIANÇA INTERPESSOAL VS. CONFIANÇA POLÍTICA}

Há outros motivos, todavia, para desconfiar do conceito de confiança interpessoal. Eles dizem respeito ao seu uso enquanto categoria para uma análise sociopolítica comparativa da estabilidade democrática e modernização econômica dos países no mundo de hoje. A confiança depositada em relações com parentes, amigos e conhecidos é certamente um componente primordial de nossa vida afetiva. Sem ela, o parentesco seria somente um formalismo aprisionante, e a amizade não existiria. Quanto aos conhecidos, a confiança que lhes depositamos va- 
ria com seu grau de proximidade e participação em nossas vidas. Assim como no caso dos amigos mais próximos, a falta de confiança leva ao fim dessa relação. Apesar de sua importância dentro do círculo dos significant others, acreditamos que a confiança interpessoal não pode ser erigida em conceito político útil a uma teoria da democracia. Mesmo assumindo que as assimetrias marcantes que outrora fundavam relações familiares, e mesmo de amizade, tenham sido mitigadas por uma ética pós-tradicional, e que, portanto, haja nelas espaço para algum tipo de igualdade, o simples fato de morarmos em sociedades de massa não permite que mecanismos sociais de gestão e deliberação se baseiem exclusivamente nesse princípio relacional. Em outras palavras, nossas democracias têm que sobreviver sem banquetes coletivos da mesma forma que nossas economias precisam crescer sem depender de que os seus trabalhadores sejam imbuídos de uma ética protestante que os inclina vocacionalmente à produtividade.

O caso da aplicação do termo trust para relações mercantis, entretanto, é diferente. $\mathrm{O}$ tomador do fiado não tem com seu credor qualquer relação necessária de afeto ou hierarquia. Substituindo a afetividade, entra o interesse. O tomador obviamente se beneficia com a oportunidade de adquirir bens sem pagar à vista, enquanto o futuro credor, a princípio, não tem nada a ganhar com a confiança que ele deposita no outro. Contudo, é interessante notar que, mesmo nesse tipo de relação, o tomador acaba pagando mais caro pela mercadoria do que se tivesse comprado à vista. Ou seja, o interesse do futuro credor é uma forma de interest (juros). Diferentemente das relações familiares e de amizade, que funcionam na base do altruísmo e da solidariedade mútua, a confiança comercial é baseada somente no interesse. Assim, devemos assumir que ela nunca é incondicional. O devedor oferece garantias e deve aceitar condições de pagamento. Devemos, portanto, isolar o problema da confiança enquanto mediadora de relações mercantis, já que neste caso ela depende diretamente não só da vontade das partes, mas principalmente das instituições econômicas que regulam empréstimos. O problema a ser abordado é o da relação entre confiança interpessoal e confiança política no plano das relações sociais que reproduzem a democracia.

A fenomenologia do ato de confiar aponta para algumas complexidades às quais o conceito de confiança interpessoal parece ser insensível. Apesar de os participantes do survey possivelmente se sentirem compelidos a responder à pergunta sobre a confiança em pessoas "em ge- 


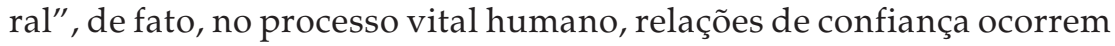
quase sempre de maneira situada. Apesar de usarmos e abusarmos intelectualmente do dualismo das categorias de público e privado, nossas relações no mundo concreto dão-se de maneira muito mais complexa. A linha que vai das pessoas íntimas às conhecidas e aos estranhos pode ser dividida em infinitas gradações. Ademais, mesmo quando a possibilidade de confiança tem como objeto pessoas estranhas, estas sempre nos aparecem em situações específicas: no trânsito, na escola de nossos filhos, na rua, no escritório, em uma manifestação política, em uma viagem etc. Em cada situação, esses estranhos se nos apresentam de maneira diversa: um guarda de trânsito, um mendigo, uma vendedora de enciclopédias, um passante etc. Cada uma dessas situações relacionais é embebida em aspectos institucionais, menos ou mais sutis, e em outros aspectos cognitivos que compõem nossa vida social.

A questão que se nos coloca, portanto, não é simplesmente a da relação entre a confiança interpessoal e a democracia, mas da consistência e utilidade de se entender o problema da democracia através da categoria da confiança interpessoal. Esse ponto pode parecer demasiadamente sutil à primeira vista, mas ele se faz fundamental para entender a perspectiva normativa aqui proposta. Trata-se de assumir uma ordem léxica entre essas duas variáveis, ou seja, de se reconhecer o primado do valor da democracia sobre qualquer aspecto da confiança que possamos usar para compreendê-la. Caso contrário, corremos o risco de concluir com Inglehart que a queda do nível de confiança interpessoal nos EUA, por exemplo, é um problema para a democracia naquele país, um raciocínio que sugere que a democracia americana era mais forte nos anos 1940 e 1950, tempos em que a maioria da população negra sequer usufruía direitos civis e políticos ${ }^{5}$. Nossa hipótese é a de que, enquanto a noção de confiança interpessoal é inadequada a uma teoria democrática moderna, a confiança em instituições é uma categoria central à compreensão da estabilidade e legitimidade de regimes democráticos. Para prosseguir com este exercício de diferenciação conceitual, precisamos, entretanto, definir estas duas categorias em questão. Uma definição de confiança interpessoal sintetizada a partir de pistas fornecidas pelo texto de Inglehart assumiria a seguinte forma: é a expectativa depositada em um estranho de que este aja de maneira cooperativa, ou, pelo menos, não danosa, em relação ao depositante. Uma definição sucinta da confiança em instituições pode ser expressa da seguinte forma: é a expectativa de ação reparatória ou punitiva por parte dos poderes estabelecidos contra todos aqueles que violarem os precei- 
tos da lei. É claro que a confiança institucional pode ser estendida para aspectos relacionados a direitos positivos de participação e deliberação política, direitos econômicos redistributivos, direitos de preservação cultural e do meio ambiente etc. Essa definição mínima, porém, nos parece suficiente para demonstrar nosso argumento.

Agora imaginemos um respondente qualquer do survey de Inglehart confrontando a pergunta sobre a confiança em pessoas "em geral". Ora, não seria absurdo inferir que, quanto maior a confiança política dessa pessoa em instituições - no caso específico de nossa definição mínima, na polícia e no Judiciário--, maior a confiança interpessoal que ela tenderá a demonstrar. Ou seja, o aspecto cognitivo de viver em um ambiente social no qual a lei impera deve contribuir fortemente para o aumento da confiança interpessoal, uma vez que durante sua vida o respondente tem chances de observar a punição consistente daqueles que infringem os preceitos da lei. $\mathrm{Ou}$, colocando o problema em termos da teoria da escolha racional, dado que a confiança em geral pode ser também entendida como uma expectativa que se pondera contra um risco, quanto menor o risco envolvido na transação, maior a confiança. As instituições políticas entram nessa equação como fatores de diminuição do risco, seja pela inibição prévia de potenciais quebradores de confiança, pela garantia de punição daqueles que realmente a quebram, ou pela possibilidade de reparação dos danos causados por uma eventual quebra de confiança.

Contudo, Inglehart não está interessado em explorar a questão da confiança política em instituições, e pensa poder controlar essa variável através do uso do índice de democracia formulado pela Freedom House. Mas o uso de tal índice está longe de dar conta das possíveis interações e distinções entre os dois níveis de confiança (interpessoal e política), seja para casos particulares ou para a amostra em geral. Vários autores, contudo, têm apontado para a necessidade imperativa de se distinguir claramente entre o conceito de confiança interpessoal e o conceito de confiança política.

Kenneth Newton (1999), por exemplo, demonstra que a confiança interpessoal, quando se analisam os dados do World Surveys e dos Eurobarometers e se comparam a outros surveys que medem confiança política (entendida genericamente como confiança nas instituições governamentais), produzem resultados contraditórios, o que sugere que se tratam de duas dimensões distintas. Mais importante ainda, demonstra 
Newton, quando se analisam estes dados no plano intranacional, a confiança interpessoal está positiva e fortemente correlacionada com renda e escolaridade, o que sugere que quem expressa altos graus deste tipo de confiança são "os vencedores na sociedade" (winners in society). Já a confiança política não apresenta nenhuma correlação forte com ser ou não membro das elites de uma sociedade. Curiosamente, também não há nenhuma correlação forte entre participação política em associações voluntárias e confiança política.

Estes dados e análises de Newton sugerem não só a existência de duas dimensões distintas do conceito de confiança (interpessoal e política), mas a irrelevância da primeira dimensão para uma compreensão da estabilidade democrática. É a segunda dimensão (a da confiança política nas instituições) que, por apresentar resultados ambíguos e independentes de renda e escolaridade, requer uma análise e compreensão mais aprofundada.

Um argumento semelhante é apresentado por Kenneth P. Ruscio (1999). Segundo o autor, confiança pessoal (personal trust) e confiança política (political trust) não podem ser confundidas. Enquanto o conceito de confiança pessoal, tal qual apresentado por autores como Hardin (1993; 1996), é pensado como "noção amoralizada" (unmoralized notion), indicando apenas uma decisão pessoal de outorgar autoridade a outrem, o conceito de confiança política, que às vezes aparece travestido em Hardin na forma do conceito de trustworthiness (merecer confiança), implica aprovação moral por parte daquele que confia. Ora, se o conceito de confiança (inter)pessoal indica apenas o sentido original da palavra latina fides, retornamos ao âmbito de relações mercantilizadas, e não há sequer porque chamar esta relação de con-fiança, uma vez que se trata apenas de um interesse encapsulado que pode ser maximizado através da minimização dos riscos da transação. O problema de quem merece confiança (trustworthiness), por sua vez, não pode ser desvinculado da posição institucional ocupada pelo sujeito dentro do conjunto das relações de poder de uma sociedade. Nas sociedades pós-tradicionais, esta confiança política, na verdade, não é uma confiança na pessoa em si (pode até ser em contextos carismáticos), mas uma confiança na instituição que a media, no cargo que a pessoa ocupa, ou até mesmo na capacidade do exercício competente da função atribuída. O tema que precisa ser tratado criticamente, portanto, é o da confiança política nas sociedades contemporâneas: entender as causas 
de sua variação (intra e internacional), as possíveis formas de produzi-la e sua relação com a consolidação democrática.

\section{DEMOCRACIA E CONFIANÇA}

Discutimos anteriormente o primado da confiança em instituições sobre a confiança interpessoal na construção de uma teoria democrática para as sociedades contemporâneas. Falta-nos, porém, definir o modelo de democracia que temos em mente. Não nos interessa aqui desenvolver uma teoria completa da democracia, mas somente ressaltar alguns aspectos necessários às suas instituições. Ao nosso ver, as instituições em um regime democrático devem servir como espaços de discussão, deliberação e/ou adjudicação de três tipos de demandas sociais: reconhecimento, redistribuição e revisão das regras das próprias instituições.

A questão do reconhecimento tem recebido grande atenção na literatura contemporânea sobre teoria democrática. Charles Taylor (1992) foi o pioneiro da reintrodução desse conceito de origem hegeliana no vocabulário teórico político atual. O problema levantado por esse autor é o de se pensar o funcionamento de uma democracia moderna em uma sociedade multicultural, isto é, dividida em comunidades que não compartilham dos mesmos valores e modos de vida ${ }^{6}$. Taylor argumenta que indivíduos e grupos étnicos só podem usufruir uma vivência digna dentro de uma comunidade política nacional se eles têm, de alguma maneira, o valor de seu estilo de vida (etos, cultura) reconhecido por essa mesma comunidade. Na linguagem corrente da chamada "virada lingüística", isto se concretiza através do compartilhamento intersubjetivo de formas lingüísticas propícias ao reconhecimento. Mas a constatação teórica da necessidade do reconhecimento não oferece uma solução imediata para o problema político da democracia em uma sociedade multicultural, pois, na prática há o problema da valoração comparativa de diferentes culturas. Taylor rejeita a tese de que todas as culturas têm o mesmo valor, e, portanto, a conclusão de que todas a minorias étnicas devam ser agraciadas com os direitos necessários para sua preservação. Em seu lugar, o autor propõe uma abordagem hermenêutica para o problema, na qual a cultura dominante se abre ao estudo dos outros e, através dessa abertura, se permite examinar criticamente a sua própria identidade, modificando assim seu horizonte de valores. Apesar da beleza quase poética da proposta, devemos notar que ela pressupõe um entendimento prévio do eu (self) cultural dominante e, 
por conseguinte, dos outros; ou, em termos gadamerianos, um estado inicial que precede o momento hermenêutico em que há um entendimento intersubjetivo da própria tradição. Discordamos que deva haver tal momento inicial em uma teoria democrática. Ou melhor, pensamos ser possível cogitar uma alternativa que, sem descartar a questão do reconhecimento, não passe pela reificação da cultura do eu e do outro e, portanto, não exija que as pessoas para serem incluídas tenham que se apresentar como o Outro de sua própria comunidade política.

Axel Honneth (1995) avança em relação a Taylor ao reconstruir uma teoria da democracia moderna baseada na questão do reconhecimento. Para Honneth, o reconhecimento não é somente um problema de minorias, mas a base sobre a qual se deve assentar a formação da personalidade, do indivíduo como portador de direitos e do cidadão. Segundo o autor, há três tipos básicos de reconhecimento: o amor e afeto que uma pessoa recebe de seus significant others, o respeito dos direitos iguais de cada pessoa e o reconhecimento do estilo de vida de cada um como uma contribuição original à vida social. Essas formas de reconhecimento operam através de processos intersubjetivos de comunicação e são responsáveis por produzir na pessoa a auto-estima, a autoconfiança e o respeito próprio. A tipologia do reconhecimento de Honneth tem um aspecto normativo forte, pois funciona ao mesmo tempo como um horizonte ético da vida do indivíduo em sociedade e como um conjunto de critérios através do qual instituições públicas podem ser construídas, reformadas ou banidas.

Concordamos com Honneth em outorgar importância à questão do reconhecimento. Nosso ponto de vista difere do dele, porém, na medida em que pensamos que, em uma sociedade verdadeiramente democrática, o conteúdo substantivo do reconhecimento só pode ser definido através da prática política, entendida como atos comunicativos de participação e deliberação em situações de ação concreta. Ou seja, o esforço de se definir o conteúdo do reconhecimento como um a priori teórico é contrário ao princípio democrático. Portanto, o aperfeiçoamento das instituições políticas não se faz perseguindo formas fixas de reconhecimento, mas sim proporcionando canais através dos quais as pessoas possam resistir ao que elas entendem como falta de reconhecimento (desrespeito). Dessa maneira, tanto o indivíduo como um coletivo de pessoas podem reclamar pelo tratamento que lhes pareça mais justo (respeitoso) sem ter que se limitar a uma concepção saudável de reconhecimento. O que importa, portanto, do ponto de vista de uma teoria 
política normativa que opera sob o horizonte democrático, é identificar formas retóricas através das quais o desrespeito é produzido no uso da linguagem cotidiana e das linguagens técnicas das disciplinas científicas (Feres Júnior, 2002).

Uma das críticas mais interessantes à posição de Honneth foi articulada por Nancy Fraser (1997). Fraser reconhece a importância das demandas por reconhecimento em sociedades modernas, mas chama atenção para a importância das demandas por distribuição. De acordo com a autora, uma concepção de justiça democrática não pode abrir mão de qualquer desses dois eixos de reivindicação. Segundo Fraser, a teoria da democracia baseada no reconhecimento proposta por Honneth e Taylor acaba por reduzir o problema da democracia a questões de política da identidade, excluindo assim as demandas por redistribuição, que foram o motor de grande parte dos movimentos sociais democratizantes no Ocidente. Ademais, no plano dos movimentos sociais contemporâneos, questões de reconhecimento e redistribuição não raro se encontram entrelaçadas, como é o caso, por exemplo, das demandas contra formas de exploração econômica baseadas em gênero e raça. Por fim, Fraser também chama atenção para o fato de que a luta pelo reconhecimento deve abarcar não só demandas pela proteção de identidades, mas também movimentos que propõem a desconstrução do essencialismo que move a "política da identidade", como por exemplo queer politics, o feminismo desconstrutivista, e a teoria crítica da raça (Fraser, 1997; Fraser e Honneth, 2003).

Ora, não podemos ignorar o fato de que os outros das democracias modernas, aqueles que têm um déficit de reconhecimento, são quase sempre os mesmos que sofrem de injustiça distributiva. Não há, portanto, como discordar de Fraser a respeito da necessidade de se contemplar tanto o reconhecimento como a distribuição em uma teoria democrática. Pensamos, porém, que, no tocante às instituições, é importante ressaltar a necessidade de suas normas também estarem submetidas ao procedimento democrático, isto é, a discussão, deliberação e revisão.

Para tanto, podemos usar o recurso contrafactual, como faz Habermas (1996), e argumentar que a ausência de espaços institucionais para que qualquer uma das demandas (reconhecimento, redistribuição e revisão de normas) possa ser discutida publicamente comprometeria seriamente o caráter democrático de qualquer regime. No modelo de democracia habermasiano, a construção dos procedimentos discursivos 
recebe um tratamento nitidamente deontológico, em que os princípios da ética do discurso (princípios U e D) são tratados como momentos indisponíveis à discussão pública, já que seu questionamento resultaria naquilo que Habermas denomina de "contradição performativa", isto é, o agente que recusa estes princípios em um contexto comunicativo precisa, ao mesmo tempo, aceitá-los para conferir pretensão de validade a esta recusa. Entretanto, este tratamento deontológico aos procedimentos discursivos é ele, também, vítima de uma contradição performativa, pois se os próprios princípios da construção da autonomia privada não podem estar sujeitos ao exercício pleno da soberania popular, caímos novamente em um modelo liberal de democracia, em que tolerância (e a confiança interpessoal que ela pressupõe) se sobrepõe à confiança nas instituições. Em suma, os próprios procedimentos discursivos - i.e., as normas fundamentais - precisam estar sujeitos à possibilidade de revisão por parte das comunidades democráticas ${ }^{7}$.

Mas qual é, afinal de contas, a utilidade e a importância de incluirmos a confiança política em instituições na produção de um modelo contemporâneo de democracia? Essa categoria serve como ponte entre uma teoria normativa de democracia e a realidade das democracias existentes no mundo contemporâneo. Por mais irônico que pareça, a confiança em instituições pode ter uma importante aplicação em ciência política, funcionando como ferramenta de medição do teor democrático de regimes políticos concretos. Esse procedimento funcionaria como importante contraponto, ou complemento, para análises institucionalistas, que supõem poder determinar níveis de democracia através do estudo do desenho e desempenho de instituições.

Para que isso seja feito, no entanto, é necessário que esse tipo de confiança seja dividido de acordo com os tipos de demanda supracitados. Em vez de conter perguntas sobre a confiança política em geral, surveys de opinião pública devem ter blocos de perguntas sobre a confiança em instituições quanto a demandas por redistribuição, reconhecimento e revisão de normas, separadamente. Por exemplo, um cidadão em um país rico, com sistema de seguridade social consolidado, pode confiar nas instituições que atendem demandas por redistribuição ao mesmo tempo em que desconfia do sistema político, por esse não estar aberto a demandas por maior participação e deliberação (normas). Outra pessoa pode se sentir desrespeitada como membro de uma minoria cultural e alijada de processos redistributivos e ao mesmo tempo confiar nas regras do jogo político. Em outras palavras, a dimensão "confiança po- 
lítica" é a dimensão pertinente, e ela precisa ser medida e especificada para os três níveis com os quais demandas sociais interagem.

Em suma, se queremos construir sociedades democráticas tomando como ponto de partida a realidade das democracias existentes e a realidade das demandas sociais feitas em seu seio, precisamos reintroduzir a dimensão "confiança política", entendida como a confiança que o corpo de cidadãos deposita nas instituições responsáveis pelo reconhecimento, participação e distribuição de riqueza. O ato de confiar é muito mais complexo e contém inúmeras sutilezas que uma simples pergunta sobre o grau de confiança interpessoal entre os cidadãos de um país jamais será capaz de captar. Ignoradas esta complexidade e estas sutilezas, fica a impressão, pelo menos entre os mais céticos quanto à validade das incursões da política comparada no campo da teoria democrática, de que estamos dormindo com o inimigo.

(Recebido para publicação em fevereiro de 2006)

(Versão definitiva em agosto de 2006)

\section{NOTAS}

1. O presente texto visa, portanto, a uma crítica analítica do conceito de confiança interpessoal, não investindo na análise da literatura empírica que trata dos níveis de confiança interpessoal em nosso país. Para tal, vide, por exemplo, Avritzer (1995; 2001; 2002), Baquero (2001; 2003) e Singer (1999).

2. Sobre os problemas da tradução e sua importância para uma compreensão das interações lingüísticas em geral, ver Gadamer (1975, esp. pp. 346-347)

3. Mantivemos o inglês da citação porque a tradução para o português para este trecho do cap. X do Leviatã na edição da coleção Os Pensadores omite a palavra "confiar" (trust): "Honrar aquele a quem outro honra é honrar este também, como sinal de aprovação de seu discernimento. Honrar seus inimigos é desonrá-lo". Ver Hobbes (1983:55).

4. Aqui o argumento é similar ao de Hobbes. Locke defende que o pátrio poder só se justifica pela imaturidade e, portanto, racionalidade incompleta dos filhos. Uma vez que as faculdades da razão se desenvolvem, as bases do poder da relação familiar se extinguem.

5. Para uma crítica detalhada do conservadorismo dessa posição, ver Cohen (1999).

6. A questão prática que move o esforço de Taylor (1992) é o da democracia em um Canadá dividido entre anglófonos, francófonos e outras minorias. 
7. De acordo com o princípio (U) da ética do discurso de Habermas, toda norma deve satisfazer a condição que as "conseqüências e efeitos colaterais, que (possivelmente) resultarem para a satisfação dos interesses de cada um dos indivíduos do fato de ser ela universalmente seguida, possam ser aceitos por todos os concernidos (e preferidos a todas as conseqüências das possibilidades alternativas e conhecidas de regragem)". Já o princípio (D) afirma que todos aqueles potencialmente afetados pela norma cheguem a um acordo quanto a sua validez (Habermas, 1989:86).

\section{REFERÊNCIAS BIBLIOGRÁFICAS}

ALMOND, Gabriel Abraham e COLEMAN, James Smoot. (1960), The Politics of the Developing Areas. Princeton, Princeton University Press.

ALMOND, Gabriel Abraham e VERBA, Sidney. (1963), The Civic Culture: Political Attitudes and Democracy in Five Nations. Princeton, Princeton University Press.

ANDREWS, E. A., FREUND, William, LEWIS, C. T. eSHORT, C. (1955), A Latin Dictionary Founded on Andrews' Edition of Freund's Latin Dictionary: Rev., Enl., and in Great Part Rewritten. Oxford, Clarendon Press.

AVRITZER, Leonardo. (1995), “Cultura Política, Atores Sociais e Democratização”. Revista Brasileira de Ciências Sociais, $\mathrm{n}^{-}$28, pp. 109-122.

. (2001), "O Pano de Fundo da Crise é a Concepção de Aliança Política de FHC". Conjuntura Política, no 26, pp. 1-4.

. (2002), Democracy and the Public Space in Latin America. Princeton, Princeton University Press.

BAQUERO, Marcelo. (2001), “Cultura Política Participativa e Desconsolidação Democrática: Reflexões sobre o Brasil Contemporâneo". São Paulo em Perspectiva, vol. 15, no 4, pp. 98-104.

. (2003), “Construindo uma Outra Sociedade: O Capital Social na Estruturação de uma Cultura Política Participativa no Brasil". Revista de Sociologia Política, nº 21, pp. 83-108.

BLANKSTEN, George. (1960), “The Politics of Latin America”, in G. Almond e J. S. Coleman (orgs.), The Politics of Developing Areas. Princeton, Princeton University Press.

COHEN, Jean. (1999), “Trust, Voluntary Association and Workable Democracy: The Contemporary American Discourse of Civil Society", in M. E. Warren (org.), Democracy and Trust. Cambridge, Cambridge University Press.

FERES JÚNIOR, João. (2002), “Contribuição a uma Tipologia das Formas de Desrespeito: Para Além do Modelo Hegeliano-Republicano". Dados, vol. 45, nº 4, pp. 555-675.

FRASER, Nancy. (1997), Justice Interruptus: Critical Reflections on the "Postsocialist" Condition. New York, Routledge. 
e HONNETH, Axel. (2003), Redistribution or Recognition? A Political-Philosophical Exchange. London, Verso.

FUKUYAMA, Francis. (1995), Trust: The Social Virtues and the Creation of Prosperity. New York, Free Press.

GADAMER, Hans. (1975), Truth and Method. New York, Seabury Press.

HABERMAS, Jürgen. (1989), Moral Consciousness and Communicative Action. Cambridge, MIT Press.

(1996), Between Facts and Norms: Contribution to a Discourse Theory of Law and Democracy. Cambridge, MIT Press.

HARDIN, Russell. (1993), "The Streetlevel Epistemology of Trust". Politics and Society, no 21, pp. 505-529. (1996), "Trustworthiness". Ethics, no 107, pp. 26-42.

HOBBES, Thomas. (1983), Leviatã. São Paulo, Editora Abril (Coleção Os Pensadores).

HONNETH, Axel. (1995), The Struggle for Recognition: The Moral Grammar of Social Conflicts. Oxford/Cambridge/Massachussets, Polity Press/Blackwell.

INGLEHART, Ronald. (1999), "Trust, Well-Being and Democracy", in M. Warren (org.), Democracy and Trust. Cambridge, Cambridge University Press, pp. 88-120.

LERNER, Daniel. (1967), The Passing of Traditional Society: Modernizing the Middle East. Glencoe, Free Press.

LIPSET, Seymour Martin. (1960), "Values, Education, and Entrepreneurship", in Elites in Latin America, S. M. Lipset e A. E. Solari (eds.). New York, Oxford University Press.

LOCKE, John. (1983), Segundo Tratado sobre o Governo. São Paulo, Editora Abril (Coleção Os Pensadores).

MARTIN, David. (1990), Tongues of Fire: The Explosion of Protestantism in Latin America. Oxford/Cambridge, Blackwell.

MILLIKAN, Max F. e BLACKMER, Donald L. M. (1961), The Emerging Nations: Their Growth and United States Policy. Boston, Little Brown/Massachusetts Institute of Technology, Center for International Studies.

NEWTON, Kenneth. (1999), "Social and Political Trust in Established Democracies", in P. Norris (org.), Critical Citizens: Global Support for Democratic Government. Oxford, Oxford University Press, pp. 169-187.

PUTNAM, Robert. (1993), Making Democracy Work: Civic Traditions in Modern Italy. Princeton, Princeton University Press.

ROSTOW, W. W. (1960), The Stages of Economic Growth, a Non-Communist Manifesto. Cambridge, Cambridge University Press.

RUSCIO, Kenneth Patrick. (1999), “Jay's Pirouette, Or Why Personal Trust is Not the Same as Political Trust". Administration and Society, vol. 31, no 5, pp. 639-657.

SIMPSON, J. A., WEINER, E. S. C. et alii. (1991), The Oxford English Dictionary. Oxford/New York, Clarendon Press/Oxford University Press. 
João Feres Júnior e José Eisenberg

SINGER, André. (1999), Esquerda e Direita no Eleitorado Brasileiro: A Identificação Ideológica nas Disputas Presidenciais de 1989 e 1994. São Paulo, EDUSP / FAPESP.

TAYLOR, Charles. (1992), "The Politics of Recognition", in C. Taylor e A. Gutmann, (orgs.), Multiculturalism: Examining the Politics of Recognition. Princeton, Princeton University Press, pp. xi e 112.

WARREN, Mark (org.). (1999), Democracy and Trust. Cambridge, Cambridge University Press.

\begin{abstract}
Sleeping with the Enemy: A Critique of the Concept of Trust

In this article we intend to demonstrate that mainstream interpretations of international survey results on the value of interpersonal trust are often imprecise and mistaken, since they ignore the different roles conflict-adjudicating institutions play in mediating interpersonal relations in the societies the survey is applied, and thus the capacity this institutions have in fashioning civic and political cultures. Consequently, the answers obtained in public opinion polls referring to the concept of trust end up translating a very distinct dimension from that originally intended by those conducting the study. At the same time, the assumption that culture is an independent variable that determines social and political relations runs unchecked by the methodology and is confirmed in the final interpretation of results. In short, due to such analytical weakness, the concept of interpersonal trust is turned ineffective as a tool for empirical measurement, thus leading to erroneous nomological conclusions.
\end{abstract}

Key words: trust; civic culture; opinion polls; surveys, democratic stability 


\section{RÉSUMÉ}

\section{Coucher avec l'Ennemi: Une Critique de l'Idée de Confiance}

Dans cet article, on cherche à montrer que les interprétations des résultats obtenus dans des enquêtes internationales sur la question des valeurs, sont souvent imprécises ou erronées, puisqu'elles ne tiennent pas compte des différences importantes existant entre les sociétés étudiées quant à leurs cultures civique et politique. On avance qu'une part de cette équivoque découle de la faiblesse analytique dans l'expression du concept de confiance interpersonnelle, puisque cette expression ne prend pas en considération le rôle joué par des institutions adjugeant des conflits lors de leur médiation des relations interpersonnelles dans une société. Par conséquent, les réponses obtenues dans les enquêtes d'opinion au sujet du concept de confiance présentent une portée différente de celle prétendue à l'origine par ceux qui les mènent. Bref, l'idée est que, à cause de sa fragilité analytique, le concept de confiance interpersonnelle n'est pas valable en tant qu'outil de mesure empirique, menant donc à des conclusions nomologiques - c'est-à-dire des généralisations théoriques inductives fondées sur des évidences empiriques erronées.

Mots-clé: confiance; culture civique; enquêtes d'opinion; surveys 